\title{
Women's experiences with postpartum anxiety disorders: a narrative literature review
}

This article was published in the following Dove Press journal:

International Journal of Women's Health

\author{
Elena Ali \\ Faculty of Nursing, University of \\ Calgary, Calgary, AB, Canada
}

Correspondence: Elena Ali

Owerko Centre, Third Floor - Child

Development Centre Building, c/o 2500

University Drive NW, Calgary, AB, T2N

IN4, Canada

Tel +l 4038505442

Email alie@ucalgary.ca
Purpose: Postpartum anxiety disorders are common and may have significant consequences for mothers and their children. This review examines the literature on women's experiences with postpartum generalized anxiety disorder (GAD), postpartum panic disorder (PD), obsessive compulsive disorder (OCD), and posttraumatic stress disorder (PTSD).

Methods: MEDLINE (Ovid), CINAHL, PsycINFO, and reference lists were searched. Qualitative and quantitative studies assessing women's experiences with GAD, postpartum $\mathrm{PD}, \mathrm{OCD}$, and PTSD were included. Narrative approach to literature synthesis was used.

Results: Fourteen studies (among 44 articles) met the criteria for review to identify descriptions of women's cognitive, affective, and somatic experiences related to postpartum anxiety disorders. Loss, frustration, and guilt, accompanied by physical symptoms of tension, were some of the experiences identified across studies. Most women suffered from more than one anxiety disorder, in addition to postpartum depression. To date, research has focused on prevalence rates of postpartum anxiety disorders, and evidence about clinical and subclinical symptoms of postpartum anxiety disorders and outcomes on mother and child is lacking. Postpartum anxiety disorders may have negative effects on parenting and child development; however, the nature of the underlying mechanisms is unclear.

Conclusion: More robust longitudinal studies are needed to examine the impact of postpartum GAD, PD, OCD, and PTSD symptoms on the mother and the mother-child relationship to develop targets for therapeutic preventative interventions.

Keywords: postnatal anxiety, postnatal distress, childbirth, women's beliefs and attitudes

\section{Introduction}

"I could not walk out of the bedroom with a baby, because I was utterly convinced

I would drop him over the banisters [...] I had very clear visions of seeing his fall”.

The arrival of a new baby is an exhilarating time of great changes and new responsibilities. Becoming a mother is considered to be one of the most significant and rewarding experiences. ${ }^{2}$ For some women, however, the postpartum stage is a challenging period that is darkened by mental illness. While a certain degree of anxiety in response to becoming a new mother is normal, and even adaptive, some mothers can experience anxieties that are excessive and debilitating. ${ }^{3,4}$

To date, abundant research has focused on the clinical presentation, prevalence, etiology, and treatment of postpartum depression; however, fewer studies have examined postpartum anxiety disorders. ${ }^{5}$ Anxiety during the postpartum period is common and, even at subclinical levels, has highly detrimental and long-term effects on mothers and their infants. ${ }^{6}$ Specifically, postpartum anxiety is associated with disrupted mother-infant attachment, postpartum depression, reduced likelihood of breastfeeding, 
increased risk of infant abuse, delayed cognitive and social development in infants, and an increased likelihood of anxiety in children..$^{7-12}$ In this paper, I review and synthesize the literature as it relates to women's experiences with postpartum generalized anxiety disorder (GAD), postpartum panic disorder (PD), obsessive compulsive disorder (OCD), and posttraumatic stress disorder (PTSD).

\section{Background}

Given the magnitude of the effect of postpartum anxiety on a mother and her baby, it is important to better understand the complexity of this phenomenon. It is known that anxiety disorders are more common in postpartum women than in the general population, with estimates of its incidence during the first 6 months of postpartum ranging from $6.1 \%$ to $27.9 \%$. $^{13-15}$ Unfortunately, treatment rates for postpartum anxiety are low, suggesting that more work is required to identify women who may benefit from treatment. ${ }^{16}$ Yet, to date, there is a lack of consistent screening measures for postpartum anxiety, and there are no anxiety-specific screening instruments routinely used in the postpartum period. ${ }^{17,18}$ A further complicating problem is the issue of comorbidity between anxiety and depression, with many symptoms being similar in both disorders. ${ }^{17}$ Therefore, it is important to understand the specific symptoms of clinically significant postpartum anxiety in order to distinguish it from postpartum depression, as well as from transient, spontaneously remitting anxiety symptoms, so that effective interventions may be offered.

There is a paucity of descriptions of women's experiences with postpartum anxiety in the empirical literature. The majority of published studies comprise retrospective chart reviews, self-administered surveys, and structured clinical interviews, providing little information about the lived experiences of women with postpartum anxiety. Thus, a number of questions remain unanswered, including how women's experiences with postpartum anxiety may influence their choice to seek help, and what sort of help they may prefer. There is consequently a need to broaden the study of postpartum anxiety to include both qualitative and quantitative studies of women's experiences. Such information is needed to inform the development of prevention, screening, early intervention, and targeted maternal mental health treatment programs at the local and the national levels.

\section{Methods}

The purpose of this narrative review was to explore what is known about women's experiences with postpartum anxiety disorders and to determine gaps in knowledge on this topic. Given the heterogeneity of studies, I used a narrative approach to synthesizing literature about women's experiences with postpartum anxiety disorders. ${ }^{21} \mathrm{~A}$ narrative review is a valuable approach when one is attempting to link together heterogeneous studies on the same topic to draw conclusions about a broad perspective on the topic of interest. ${ }^{19,21}$ This type of review can help to identify gaps in a body of knowledge, generation of a hypothesis, and development of conceptual or theoretical frameworks. ${ }^{20}$ Narrative reviews tend to be mainly descriptive, do not involve systematic review of the literature, and often focus on a subsample of studies chosen based on availability or author selection. The preparation of a narrative review can benefit from applying the methodological rigor of systematic reviews. ${ }^{22}$ As such, to enhance the quality of this narrative review, well-defined questions and clear inclusion/exclusion criteria, along with description of the comprehensive search strategy, were included.

Three electronic databases were searched: MEDLINE (Ovid), CINAHL, and PsycINFO. Searches were set to publications from 1860 to 2016 in MEDLINE, 1982-2016 in CINAHL, and 1803-2016 in PsycINFO. These year ranges for the database searches were chosen with the aim to accumulate as much evidence as possible to summarize the findings of the research and to identify gaps in the literature. A combination and variations of the following terms, including appropriate subject headings and the Boolean operators (ie, AND, OR), were used: postpartum women, postnatal women, new mothers, postpartum care, postpartum anxiety, and postnatal anxiety. Additional publications were identified from a hand search of the reference lists of the included studies. The search limits were set to full text with abstract, English, peer-reviewed, and original research electronic journal publications.

Articles were included using the following criteria: 1) study population included postpartum mothers; 2) studies explored postpartum anxiety disorders; 3 ) outcomes included description of women's experiences with postpartum anxiety disorders, such as perceptions, views, beliefs, cognitions, feelings, physiological symptoms, and somatic symptoms; 4) English language; and 5) qualitative, quantitative, or mixed-method studies. Articles were excluded if 1) a study population consisted of men, children, pregnant women, or animals; 2) the focus of a study was on postpartum psychosis, postpartum depression, or prenatal anxiety; and 3) if only prevalence, incidence, and treatment for postpartum anxiety were reported, without description of women's experiences. Letters, commentaries, reviews, discussion papers, editorials, and conference proceedings were also excluded (Table 1). 
Table I Inclusion and exclusion criteria

\begin{tabular}{|c|c|c|c|}
\hline PICO & Question in PICO format & Inclusion criteria & Exclusion criteria \\
\hline Population & Postpartum women, new mothers & Postpartum women & Men, pregnant women, children, animal studies \\
\hline $\begin{array}{l}\text { Intervention } \\
\text { or exposure }\end{array}$ & Postpartum anxiety & Postpartum anxiety, GAD, PD, PTSD, OCD & $\begin{array}{l}\text { Postpartum depression, postpartum psychosis, } \\
\text { pregnancy anxiety }\end{array}$ \\
\hline Outcomes & $\begin{array}{l}\text { Women's experiences with } \\
\text { postpartum anxiety }\end{array}$ & $\begin{array}{l}\text { Psychological issues, experiences, } \\
\text { perceptions, views, cognitions, feelings, } \\
\text { physiological symptoms, somatic symptoms }\end{array}$ & Prevalence and incidence, treatment \\
\hline Study type & & Qualitative, quantitative, and mixed methods & $\begin{array}{l}\text { Letters, commentaries, review, discussion } \\
\text { paper, editorials, conference proceedings }\end{array}$ \\
\hline
\end{tabular}

Abbreviations: PICO, problem/patient/population, intervention/indicator, comparison, outcome; GAD, generalized anxiety disorder; PD, panic disorder; PTSD, posttraumatic stress disorder; OCD, obsessive compulsive disorder.

I extracted data from the included studies using a form that included study author and year; purpose, design, and setting; sample characteristics; data collection and analysis; brief results; symptoms of anxiety disorder; and limitations, among other relevant information. For a more structured approach to the assessment of the studies' quality, the Critical Appraisal Skills Program (CASP) Qualitative Research Checklist, Cohort Study Checklist, and Case-Control Study Checklist were used (Tables 2-4). ${ }^{23}$

\section{Review}

\section{Study characteristics}

From 795 potentially relevant papers (CINAHL: $n=651$, MEDLINE: $\mathrm{n}=74$, and PsycINFO: $\mathrm{n}=70$ ), I screened 749 titles/ abstracts for inclusion (Figure 1). Next, a total of 44 full-text papers were evaluated, and 14 were retained for the final synthesis based on the inclusion and exclusion criteria. Among the 14 included articles, a majority were published after $1998(n=13)$ and were from North America $(n=9)$. Studies were of qualitative $(n=6)$ and quantitative $(n=8)$ designs (Table 5). Table 6 contains a summary of the included studies.

Across all studies, 2,407 women were surveyed or interviewed, and 274 patient records were reviewed. The settings of the studies varied, including public and private health care facilities as well as the Internet. Six studies included primiparous and multiparous women $<12$ months postpartum, five studies included women $>12$ months postpartum, and in seven studies, the timing of assessment was not specified. Some researchers examined postpartum anxiety

Table 2 CASP (2017) Qualitative Research Checklist

\begin{tabular}{|c|c|c|c|c|c|c|c|c|c|c|}
\hline Study & Aims & Methods & Design & Recruitment & $\begin{array}{l}\text { Data } \\
\text { collection }\end{array}$ & Relationships & Ethics & $\begin{array}{l}\text { Data } \\
\text { analysis }\end{array}$ & Findings & Value \\
\hline Ayers, $2007^{44}$ & Yes & Yes & Yes & Yes & Yes & Cannot tell & $\begin{array}{l}\text { Cannot } \\
\text { tell }\end{array}$ & Yes & Yes & $\begin{array}{l}\text { Valuable (rich descriptions, } \\
\text { implications for future } \\
\text { research) }\end{array}$ \\
\hline Beck, $1998^{33}$ & Yes & Yes & Yes & Yes & Yes & Cannot tell & Yes & Yes & Yes & $\begin{array}{l}\text { Very valuable (study makes } \\
\text { contribution to the existing } \\
\text { knowledge, new areas of } \\
\text { research identified) }\end{array}$ \\
\hline Beck, $2004^{43}$ & Yes & Yes & Yes & Yes & Yes & Yes & Yes & Yes & Yes & $\begin{array}{l}\text { Very valuable (study makes } \\
\text { contribution to the existing } \\
\text { knowledge) }\end{array}$ \\
\hline $\begin{array}{l}\text { Clark et al, } \\
2014^{26}\end{array}$ & Yes & Yes & Yes & Cannot tell & Yes & Yes & Yes & Yes & Yes & $\begin{array}{l}\text { Valuable (implications for } \\
\text { research and practice) }\end{array}$ \\
\hline $\begin{array}{l}\text { Coates et al, } \\
2014^{27}\end{array}$ & Yes & Yes & Yes & Yes & Yes & Yes & Yes & Yes & Yes & $\begin{array}{l}\text { Very valuable (rich } \\
\text { descriptions make } \\
\text { contribution to the } \\
\text { existing knowledge) }\end{array}$ \\
\hline $\begin{array}{l}\text { Hignet et al, } \\
2014^{28}\end{array}$ & Yes & Yes & Yes & Yes & Yes & Yes & Yes & Yes & Yes & $\begin{array}{l}\text { Valuable (implications for } \\
\text { research and practice) }\end{array}$ \\
\hline $\begin{array}{l}\text { Wardrop and } \\
\text { Popadiuk, } \\
2013^{17}\end{array}$ & Yes & Yes & No & Yes & Yes & Yes & Yes & No & Yes & $\begin{array}{l}\text { Somewhat valuable } \\
\text { (identifies new areas for } \\
\text { research and policy) }\end{array}$ \\
\hline
\end{tabular}

Abbreviation: CASP, Critical Appraisal Skills Program. 
Table 3 CASP (2017) Cohort Study Checklist

\begin{tabular}{|c|c|c|c|c|c|c|c|c|c|c|c|}
\hline Study & Issue & Cohort & Exposure & Outcomes & Confounders & Follow-up & Results & Precision & Application & $\begin{array}{l}\text { Fit with } \\
\text { available } \\
\text { evidence }\end{array}$ & Implications \\
\hline $\begin{array}{l}\text { Affonso } \\
\text { et al, } \\
1988^{29}\end{array}$ & Yes & Yes & Yes & Yes & No & Cannot tell & Yes & Yes & Yes & Yes & $\begin{array}{l}\text { Specific } \\
\text { recommendations } \\
\text { for supportive } \\
\text { interventions for } \\
\text { women suffering } \\
\text { from anxiety in } \\
\text { postpartum period }\end{array}$ \\
\hline $\begin{array}{l}\text { Martini } \\
\text { et al, } \\
2015^{30}\end{array}$ & Yes & Yes & Yes & Yes & No & Yes & Yes & Yes & Yes & Yes & $\begin{array}{l}\text { Need to follow-up } \\
\text { women with } \\
\text { prenatal anxiety } \\
\text { into postpartum } \\
\text { period }\end{array}$ \\
\hline $\begin{array}{l}\text { Miller } \\
\text { et al, } \\
2015^{39}\end{array}$ & Yes & Yes & Yes & Yes & Cannot tell & Yes & Yes & Yes & Yes & Yes & $\begin{array}{l}\text { Many women } \\
\text { suffer from } \\
\text { subclinical levels } \\
\text { of anxiety in } \\
\text { postpartum period }\end{array}$ \\
\hline
\end{tabular}

Abbreviation: CASP, Critical Appraisal Skills Program.

disorders in women representative of the general population, whereas others explored it in women who were already seeking psychiatric services in a clinic setting. In summary, the heterogeneity in study time points and measures of postpartum anxiety disorders makes it challenging to draw an overall picture of the nature of postpartum anxiety. A number of different measures were used to evaluate postpartum anxiety, including semistructured interviews and several self-report scales.

Table 4 CASP (2017) Case-Control Study Checklist

\begin{tabular}{|c|c|c|c|c|c|c|c|c|c|c|c|}
\hline Study & Issue & Method & Cases & Control & Exposure & Confounders & Results & Precision & $\begin{array}{l}\text { Believe } \\
\text { the } \\
\text { results }\end{array}$ & Application & $\begin{array}{l}\text { Fit with } \\
\text { available } \\
\text { evidence }\end{array}$ \\
\hline $\begin{array}{l}\text { Abramowitz } \\
\text { et al, } 2010^{38}\end{array}$ & Yes & Yes & Yes & No & Yes & Yes & $\begin{array}{l}\text { High percentage of } \\
\text { women reported } \\
\text { experiencing } \\
\text { intrusive thoughts } \\
\text { related to their } \\
\text { baby, various } \\
\text { thoughts described }\end{array}$ & Yes & Yes & Yes & Yes \\
\hline $\begin{array}{l}\text { Arnold, } \\
1999^{36}\end{array}$ & Yes & Yes & Yes & No & Yes & No & $\begin{array}{l}\text { Description of } \\
\text { cognitive and } \\
\text { affective symptoms } \\
\text { of postpartum } \\
\text { anxiety }\end{array}$ & Yes & Yes & Yes & Yes \\
\hline $\begin{array}{l}\text { Brockington } \\
\text { et al, } 2006^{2}\end{array}$ & Yes & Yes & Yes & No & Yes & Cannot tell & $\begin{array}{l}\text { Issue of comorbidity } \\
\text { of various mental } \\
\text { health disorders } \\
\text { in the postpartum } \\
\text { period }\end{array}$ & Yes & Yes & Yes & Yes \\
\hline $\begin{array}{l}\text { Wenzel } \\
\text { et al, 200I } 32\end{array}$ & Yes & Yes & Yes & No & Yes & No & $\begin{array}{l}\text { Anxiety is a } \\
\text { common experience } \\
\text { for women within } \\
4-6 \text { months } \\
\text { postpartum, but only } \\
\text { a small percentage } \\
\text { meet DSM-IV criteria }\end{array}$ & Yes & Yes & Yes & Yes \\
\hline
\end{tabular}




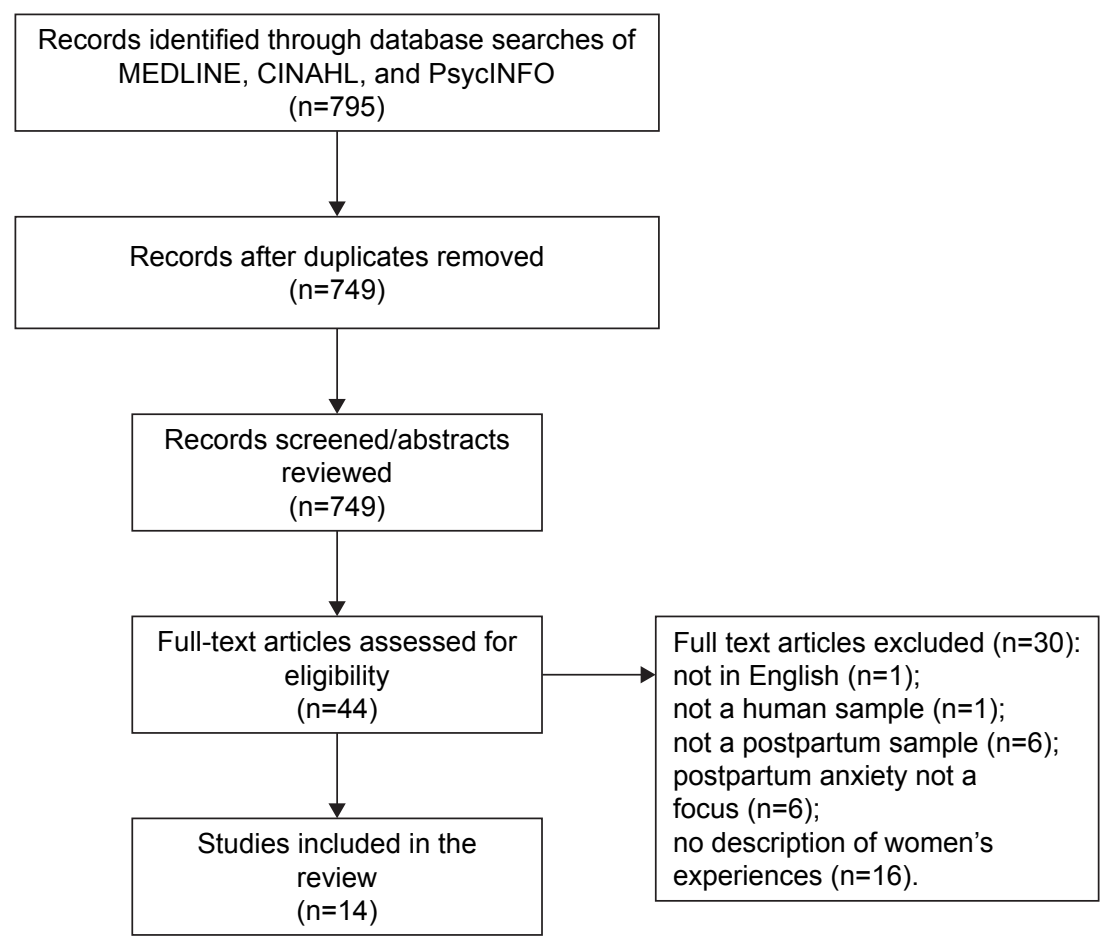

Figure I Flow diagram of review.

\section{Quality appraisal}

The qualitative studies were generally strong, apart from lack of consistency between stated methodology and analysis, ${ }^{17}$ details on participant recruitment, ${ }^{26}$ and clear descriptions of

Table 5 Study characteristics

\begin{tabular}{ll}
\hline Characteristics & Study $(\mathbf{n})$ \\
\hline Country & 7 \\
United States & 1 \\
Canada & 2 \\
Australia & 3 \\
United Kingdom & 1 \\
Germany & \\
Year range & 2 \\
1978-1998 & 12 \\
1999-20I6 & \\
Design & 6 \\
Qualitative & 8 \\
Quantitative & \\
Sample & 5 \\
$\quad<12$ months postpartum & 5 \\
$>12$ months postpartum & 4 \\
Not specified & \\
Data sources & 9 \\
Surveys, questionnaires & 1 \\
Administrative databases, patient records & 1 \\
Focus groups & 1 \\
Letters & 2 \\
Structured interviews & \\
Semistructured interviews & \\
\hline
\end{tabular}

critical evaluation of researchers' bias during data collection and analyses. ${ }^{33,44}$ In the cohort studies, ${ }^{29,30,39}$ some additional confounding factors, such as prepregnancy and/or prenatal mental health, and demographic factors such as education level, may have been important to consider. The observational studies ${ }^{2,38}$ provided valuable findings for both clinical and community-based populations.

\section{Women's experiences with postpartum anxiety disorders}

I present the key findings of the review of women's experiences with the most commonly researched postpartum anxiety disorders in five content categories: experiences with GAD, experiences with PD, experiences with OCD, and experiences with PTSD. When I use the word "experiences", I refer to one's beliefs and cognitions that are held around particular events, such as "my baby cried all night". The descriptions of cognitive (perceptions and attitudes), affective (feelings and emotions), and somatic (physical) experiential aspects of postpartum anxiety disorders are presented in this review. Further, anxiety disorders are defined as conditions that "share features of excessive fear and anxiety and related behavioral disturbances" and are differentiated by close examination of the types of situations that are feared and the content of associated beliefs. ${ }^{24}$ Each anxiety disorder has a number of relevant features that must be present to be 
Table 6 Summary of included studies

\begin{tabular}{|c|c|c|c|c|c|c|}
\hline$\overline{\text { Study }}$ & Year & Aim & Setting & Design & $\begin{array}{l}\text { Sample and timing of } \\
\text { measure }\end{array}$ & Data sources \\
\hline $\begin{array}{l}\text { Abramowitz } \\
\text { et a }\left.\right|^{38}\end{array}$ & 2010 & $\begin{array}{l}\text { To delineate } \\
\text { relationship between } \\
\text { depressive and anxiety } \\
\text { symptoms, with focus } \\
\text { on obsessional thinking } \\
\text { and behaviors }\end{array}$ & $\begin{array}{l}\text { Perinatal } \\
\text { mood } \\
\text { disorders clinic }\end{array}$ & $\begin{array}{l}\text { Descriptive, } \\
\text { cross-sectional }\end{array}$ & $\begin{array}{l}60 \text { women, } 55 \% \text { completed } \\
\text { study within 0-3 months, } \\
21 \% \text { within 3-6 months, } \\
14 \% \text { within 6-9 months, and } \\
10 \% \text { within } 9-12 \text { months } \\
\text { postpartum }\end{array}$ & $\begin{array}{l}\text { Demographic survey, } \\
\text { full assessment } \\
\text { and history, EPDS, } \\
\text { Postpartum Thoughts } \\
\text { and Behaviour Checklist } \\
\text { interview, Yale-Brown } \\
\text { Obsessive Compulsive } \\
\text { Scale, STAI, Patient } \\
\text { Health Questionnaire }\end{array}$ \\
\hline $\begin{array}{l}\text { Affonso } \\
\text { et } \mathrm{al}^{29}\end{array}$ & 1988 & $\begin{array}{l}\text { To identify differences } \\
\text { in reported stressors } \\
\text { between primiparous } \\
\text { and multiparous women }\end{array}$ & $\begin{array}{l}\text { Obstetrical } \\
\text { outpatient } \\
\text { clinic }\end{array}$ & Descriptive & $\begin{array}{l}221 \text { women, } 84 \text { primiparas } \\
\text { and I } 37 \text { multiparas, } 6 \text { weeks } \\
\text { postpartum }\end{array}$ & $\begin{array}{l}\text { Demographic } \\
\text { questionnaire, } \\
\text { structured interviews }\end{array}$ \\
\hline Arnold ${ }^{36}$ & 1999 & $\begin{array}{l}\text { To provide } \\
\text { demographic and } \\
\text { phenomenological } \\
\text { characteristics } \\
\text { of women with } \\
\text { postpartum onset of } \\
\text { obsessive compulsive } \\
\text { disorder and to evaluate } \\
\text { pharmacological } \\
\text { treatment }\end{array}$ & $\begin{array}{l}\text { Obstetrical } \\
\text { outpatient } \\
\text { clinic }\end{array}$ & Case series & 7 women, not specified & $\begin{array}{l}\text { Structured } \\
\text { clinical interview, } \\
\text { semistructured } \\
\text { interview }\end{array}$ \\
\hline Ayers $^{44}$ & 2007 & $\begin{array}{l}\text { To examine } \\
\text { development of } \\
\text { posttraumatic stress } \\
\text { symptoms }\end{array}$ & Not specified & $\begin{array}{l}\text { Mixed methods, } \\
\text { comparative }\end{array}$ & $\begin{array}{l}\text { Group I: } 25 \text { women with } \\
\text { posttraumatic stress } \\
\text { symptoms; Group II: } 25 \\
\text { women without posttraumatic } \\
\text { stress symptoms, } 3 \text { months } \\
\text { postpartum }\end{array}$ & $\begin{array}{l}\text { Posttraumatic Stress } \\
\text { Symptoms Scale, the } \\
\text { Impact of Event Scale, } \\
\text { review of medical } \\
\text { records, semistructured } \\
\text { interview }\end{array}$ \\
\hline $\begin{array}{l}\text { Brockington } \\
\text { et } \mathrm{al}^{2}\end{array}$ & 2006 & $\begin{array}{l}\text { To report on } \\
\text { diversity of psychiatric } \\
\text { postpartum illnesses and } \\
\text { to examine frequency } \\
\text { and comorbidity }\end{array}$ & Not specified & Descriptive & $\begin{array}{l}129 \text { new mothers, not } \\
\text { specified }\end{array}$ & $\begin{array}{l}\text { Demographic } \\
\text { questionnaire, } \\
\text { structured interview }\end{array}$ \\
\hline Beck $^{33}$ & 1998 & $\begin{array}{l}\text { To describe women's } \\
\text { experiences of PD in } \\
\text { postpartum period }\end{array}$ & $\begin{array}{l}\text { Women's } \\
\text { homes, public } \\
\text { places }\end{array}$ & $\begin{array}{l}\text { Colaizzi's } \\
\text { phenomenology }\end{array}$ & $\begin{array}{l}6 \text { women, } 7 \text { weeks to } 5 \text { years } \\
\text { postpartum }\end{array}$ & $\begin{array}{l}\text { Open-ended questions } \\
\text { and interviews }\end{array}$ \\
\hline Beck $^{43}$ & 2004 & $\begin{array}{l}\text { To describe the essence } \\
\text { of mothers' experiences } \\
\text { of postpartum } \\
\text { posttraumatic stress } \\
\text { disorder }\end{array}$ & $\begin{array}{l}\text { Via Internet } \\
\text { and regular } \\
\text { mail }\end{array}$ & $\begin{array}{l}\text { Colaizzi's } \\
\text { phenomenology }\end{array}$ & $\begin{array}{l}38 \text { women, } 6 \text { weeks to } \\
14 \text { years after childbirth }\end{array}$ & $\begin{array}{l}\text { Participants submitted } \\
\text { their stories via email } \\
\text { and regular mail }\end{array}$ \\
\hline Clark et $\mathrm{al}^{26}$ & 2014 & $\begin{array}{l}\text { To understand } \\
\text { how new mothers } \\
\text { experience and manage } \\
\text { distress }\end{array}$ & Not specified & Grounded theory & $\begin{array}{l}105 \text { women in focus groups, } \\
22 \text { women completed } \\
\text { interviews }\end{array}$ & $\begin{array}{l}\text { General Health } \\
\text { Questionnaire, focus } \\
\text { group discussions, } \\
\text { semistructured } \\
\text { interviews, field notes }\end{array}$ \\
\hline $\begin{array}{l}\text { Coates } \\
\text { et } \mathrm{al}^{27}\end{array}$ & 2014 & $\begin{array}{l}\text { To explore how women } \\
\text { experienced the range } \\
\text { of emotional distress } \\
\text { states in the first year } \\
\text { postpartum }\end{array}$ & $\begin{array}{l}\text { Women's } \\
\text { homes or over } \\
\text { the phone }\end{array}$ & $\begin{array}{l}\text { Interpretative } \\
\text { phenomenological } \\
\text { analysis }\end{array}$ & $\begin{array}{l}17 \text { women within first year } \\
\text { postpartum }\end{array}$ & $\begin{array}{l}\text { Semistructured } \\
\text { interviews }\end{array}$ \\
\hline $\begin{array}{l}\text { Hignet } \\
\text { et } \mathrm{a}^{28}\end{array}$ & 2014 & $\begin{array}{l}\text { To understand women's } \\
\text { experiences with } \\
\text { postpartum depression } \\
\text { and anxiety }\end{array}$ & Not specified & Grounded theory & $\begin{array}{l}28 \text { women within } \\
0-60 \text { months postpartum }\end{array}$ & $\begin{array}{l}\text { Semistructured } \\
\text { interviews }\end{array}$ \\
\hline
\end{tabular}


Table 6 (Continued)

\begin{tabular}{|c|c|c|c|c|c|c|}
\hline Study & Year & Aim & Setting & Design & $\begin{array}{l}\text { Sample and timing of } \\
\text { measure }\end{array}$ & Data sources \\
\hline $\begin{array}{l}\text { Martini } \\
\text { et } \mathrm{al}^{30}\end{array}$ & 2015 & $\begin{array}{l}\text { To examine risk factors, } \\
\text { correlates, and course } \\
\text { patterns of anxiety and } \\
\text { depressive disorders } \\
\text { during pregnancy and } \\
\text { postpartum }\end{array}$ & $\begin{array}{l}\text { Gynecological } \\
\text { outpatient } \\
\text { clinic }\end{array}$ & $\begin{array}{l}\text { Prospective, } \\
\text { longitudinal }\end{array}$ & $\begin{array}{l}274 \text { women, postpartum } \\
\text { assessments at } 10 \text { days and at } \\
2,4 \text {, and } 16 \text { months }\end{array}$ & $\begin{array}{l}\text { International Diagnostic } \\
\text { Interview, Premenstrual } \\
\text { Symptoms Screening } \\
\text { Tool, Social Support } \\
\text { Questionnaire, } \\
\text { Partnership } \\
\text { Questionnaire, } \\
\text { Rosenberg Self- } \\
\text { Esteem Scale, General } \\
\text { Self-Efficacy Scale, } \\
\text { medical records } \\
\text { review, demographic } \\
\text { questionnaire }\end{array}$ \\
\hline Miller et $\mathrm{al}^{39}$ & 2015 & $\begin{array}{l}\text { To describe prevalence } \\
\text { of obsessive-compulsive } \\
\text { symptoms during } \\
\text { postpartum period }\end{array}$ & Not specified & $\begin{array}{l}\text { Prospective } \\
\text { cohort }\end{array}$ & $\begin{array}{l}46 \mathrm{I} \text { women, screened at } \\
2 \text { weeks and } 6 \text { months } \\
\text { postpartum }\end{array}$ & $\begin{array}{l}\text { Yale-Brown Obsessive } \\
\text { Compulsive Scale, } \\
\text { STAI, Patient Health } \\
\text { Questionnaire }\end{array}$ \\
\hline $\begin{array}{l}\text { Wardrop } \\
\text { and } \\
\text { Popadiuk }^{17}\end{array}$ & 2013 & $\begin{array}{l}\text { First-time mothers' } \\
\text { experiences with } \\
\text { postpartum anxiety }\end{array}$ & $\begin{array}{l}\text { University and } \\
\text { participants' } \\
\text { homes }\end{array}$ & $\begin{array}{l}\text { Feminist } \\
\text { biographical } \\
\text { approach }\end{array}$ & $\begin{array}{l}6 \text { women within } 6 \text { months to } \\
3 \text { years postpartum }\end{array}$ & $\begin{array}{l}\text { Semistructured } \\
\text { interview }\end{array}$ \\
\hline $\begin{array}{l}\text { Wenzel } \\
\text { et } \mathrm{al}^{32}\end{array}$ & 2001 & $\begin{array}{l}\text { To investigate } \\
\text { prevalence of panic and } \\
\text { obsessive compulsive } \\
\text { symptoms in a sample } \\
\text { of postpartum women }\end{array}$ & Via telephone & $\begin{array}{l}\text { Descriptive } \\
\text { cohort }\end{array}$ & 788 women, not specified & $\begin{array}{l}\text { Structured clinical } \\
\text { interview via telephone }\end{array}$ \\
\hline
\end{tabular}

Abbreviations: EPDS, Edinburgh Postnatal Depression Scale; PD, panic disorder; STAI, State-Trait Anxiety Inventory.

considered a clinical disorder, as well as specific duration criteria, meaning that elevated anxiety alone is not sufficient to meet diagnostic criteria. ${ }^{24}$ Further, anxiety disorders tend to be highly comorbid. ${ }^{15}$

\section{Characteristics of GAD}

This anxiety disorder is a condition characterized by excessive worry that lasts for at least 6 months and is accompanied by restlessness, fatigue, poor concentration, muscle tension, and sleep disturbance. ${ }^{24}$ The prevalence of GAD in the general population is $2.9 \%$, with females being twice as likely as males to be affected. ${ }^{25}$ In postpartum women, GAD may be more common than among the general population, with the prevalence ranging from $4.4 \%$ in a community-based sample of 68 women to $8.2 \%$ in a sample of 147 women at 6-8 weeks postpartum. ${ }^{13,15}$ Wenzel et al ${ }^{13}$ found that $19.7 \%$ of women displayed symptoms of subsyndromal GAD, meaning that although the participants fulfilled the Diagnostic and Statistical Manual of Mental Disorders (DSM)-5 diagnostic criteria for the disorder, their symptoms did not cause significant life interference or distress. As a result, these measurements make it difficult to differentiate between normal and clinical levels of anxiety in the postpartum period and may result in the pathologizing of normal components of new motherhood. Therefore, it is possible that there could be a difference between women's lived experiences of anxiety in the postpartum period, whether those symptoms are problematic to women or a normal part of motherhood, and how those experiences are reported subject to current measurements.

\section{Women's experiences with GAD}

Women's experiences with GAD were described in four qualitative $e^{17,26-28}$ and three quantitative studies. ${ }^{2,29,30}$ Coates et $\mathrm{al}^{27}$ undertook an interpretative phenomenological analysis of data derived from semistructured interviews with 17 women who experienced psychological difficulties in the first year after childbirth. Seven mothers disclosed a previous mental health issue. While the study was not diagnostic in nature, participants reported feeling debilitated by symptoms of anxiety. Participants expressed feelings of guilt, avoidance, distancing and were completely distressed and overwhelmed by the responsibilities of motherhood. Accessing support and help was described as difficult; however, when participants were able to speak to other women in similar situations, they found it invaluable: "not to feel like you are the only one who's completely mad having a baby". ${ }^{17}$ 
Lack of social and health practitioner support was also identified as an important factor in the experiences of anxiety among six Canadian first-time mothers. ${ }^{17}$ From the in-depth interviews, the researchers concluded that participants felt misunderstood and alienated because their symptoms - worries, feelings of dissociations, guilt, and being overwhelmed - did not fit the dominant discourse of postpartum depression. However, the study had some methodological flaws, for example, the researchers claimed to use the feminist biographical approach but, in fact, utilized hermeneutic inquiry as the approach to data collection and analysis. Data were generated by onetime only narrative interviews, and the analysis included a very procedural method of coding data, which is not compatible with Heideggerian hermeneutic inquiry. ${ }^{17}$ In another study of 28 Australian mothers, the researchers applied the grounded theory approach to analyzing participants' responses from semistructured interviews and described the experience of postpartum anxiety as "loss" and "frustration". ${ }^{28}$ The symptoms of anxiety, although distinct, were often not sufficiently differentiated by health care providers and women themselves from the symptoms of postpartum depression, causing participants greater confusion and apprehension. ${ }^{28}$ The participants who had given birth within the past 5 years and self-reported as having experienced postpartum anxiety, felt restless, unable to make decisions, fatigued, angry, overwhelmed, and had difficulty sleeping. The women experienced excessive worries that focused on baby's well-being, feelings of disconnect, and agoraphobia (avoidance of social situations). Similar to Coates et $\mathrm{al}^{27}$ and Wardrop and Popadiuk, ${ }^{17}$ the researchers suggested that a significant discrepancy between women's expectations and beliefs and their actual experiences of motherhood may have facilitated the development of feelings of anxiety. ${ }^{28}$ While the aforementioned studies included mostly white, middle class, educated women, postpartum distress appears to manifest similarly in South Asian mothers, who suffer from gender-based, economic, and social disadvantages in their home country. In a grounded theory study, researchers conducted focus groups and individual interviews with 105 women in rural Nepal and applied a grounded theory approach to conceptualize postpartum anxiety as "tension". ${ }^{26}$ Postpartum anxiety was described in terms of physical symptoms such as disturbed sleep, palpitations, body aches, fatigue, numbness, and tingling, and cognitive symptoms such as poor concentration, inability to make decisions, self-blame, and suicidal thoughts. ${ }^{26}$ However, because the researchers used focus groups to collect data, a possible limitation of their findings was the possibility of social desirability in participants' responses.
In these qualitative studies, the researchers provided information about what women themselves considered impairing in their postpartum experiences. Symptoms focused on infant safety and well-being, infant care, and the perceived inability to meet the social ideal of a perfect mother, along with somatic symptoms of fatigue, insomnia, and restlessness were prominent. The desire to share feelings in groups and on a one-to- one basis was universal. However, the results of these studies may be limited due to the participants being self-selected and, in all but one study, ${ }^{26}$ being mostly white, employed before having a baby, welleducated, and in long-term relationships. Further studies on women of different ethnicities and relationship status would be beneficial to expand on the findings. The studies were not diagnostic in nature; therefore, no differentiating diagnoses could be made between postpartum anxiety and postpartum depression. Specifically, the participants may not have been suitable for informing this particular research, as it is unclear whether they had experiences with the phenomenon under investigation. Moreover, because in all of the studies, the data were collected at one time point only, the findings could lead to inclusion of women whose emotional distress was transient and would dissipate over time on its own. It is common for new mothers to experience anxiety as they adjust to the many physical, emotional, and psychological demands of motherhood. ${ }^{31}$

Brockington et $\mathrm{al}^{2}$ noted that the focus of maternal worry is often limited to the topics of motherhood and the baby; thus, some women, despite being significantly distressed, may not meet existing criteria for an anxiety disorder. In this study of 129 mothers, recruited from an obstetrical psychiatric clinic, postpartum anxiety was diagnosed by structured clinical interview, wherein the frequency of anxiety "themes" were noted and rated, and the degree of anxiety was assessed on a five-point scale (none, mild, moderate, severe, and incapacitating). The interviews were conducted by various research assistants, and the interview probes did not include a detailed exploration of individual symptoms, as required by DSM-IV. Anxiety was found to be moderate in 56 mothers (43\%) and severe in 18 (14\%), with the most frequent themes being fear of baby's death (32\%), fear of criticism from others $(19 \%)$ - which was associated with emotional distancing from the infant $(p<0.001)$; and fear of lack of support from partner $(16 \%){ }^{2}$ However, because this study was conducted in highly selected participants who were receiving psychiatric treatment, it makes it difficult to draw conclusions and generalize its results about anxiety to the community-based postpartum population. 
In a prospective-longitudinal study of 274 German mothers, researchers used the Composite International Diagnostic Interview for Women (CIDI-V) to assess anxiety disorders throughout pregnancy and at 10 days, as well as at 2, 4, and 16 months postpartum..$^{30}$ The strongest predictor for postpartum anxiety was prepregnancy anxiety $(95 \% \mathrm{CI}$ $[2.99,10.26], p<0.001)$, and 58 women were identified as being affected by postpartum anxiety. ${ }^{30}$ The participants reported worries about health of the baby, worries about work and school performance, worries about breastfeeding, and worries about life in general. Interestingly, women with a history of GAD prior to pregnancy reported a shift in their feared situations, such as unspecific fears about the health of family members shifting to more specific fears about health of the baby. ${ }^{30}$ While the sample size in this study was small, the variable pattern of anxiety suggests that postpartum anxiety is complex, and different trajectories of anxiety from prepregnancy to postpartum may be expected.

Affonso et $\mathrm{al}^{29}$ investigated the possible effect of parity on postpartum anxiety in a study of 84 primiparous (35.8\%) and 137 multiparous $(64.2 \%)$ women at 6 weeks postpartum. The researchers used structured interviews, analyzed data by categorizing responses, and calculating means for frequency and intensity of responses. The most frequently reported and intensely rated categories of responses for both groups were concerns over the health of the baby, with multiparas reporting a higher degree of stress related to social situations (ie, reactions of friends and strangers to new baby, decreased socialization) as compared to primiparas $(p=0.001)$. The researchers highlighted the need to tailor postpartum care to meet the needs of multiparous women..$^{29}$ However, the sample consisted of more multiparas, and the $p$-values were based on the calculation of mean scores of participants' responses, which may not provide information about specific, individual responses. Moreover, because the findings were correlational, a direct cause-and-effect relationship between parity and anxiety could not be established.

To conclude this section on GAD, it seems logical that the postpartum period would be a time of risk for development of GAD, as women may be overwhelmed by new responsibilities, roles, and multiple demands. While the studies were limited by small sample sizes and a lack of diagnostic tools, the findings suggest that there may be a large number of women who experience a significant amount of nervousness and worry associated with caring for their infant. Without doubt, there is a need to determine whether GAD has unique characteristics and onset in new mothers.

\section{Characteristics of PD}

PD is characterized by sudden and recurrent panic attacks, with symptoms typically including shortness of breath, palpitations, chest pain, dizziness, and fear of dying. ${ }^{24}$ The prevalence rates of $\mathrm{PD}$ in the general population range from $1.5 \%$ to $3.5 \%{ }^{24}$ The postpartum period represents a time of great risk for the worsening of panic symptoms in women with preexisting PD, as well as for women without a previous history. ${ }^{13}$

\section{Women's experiences with postpartum PD}

Wenzel et a ${ }^{32}$ reported that $11 \%(n=87)$ of their communitybased sample of 788 women who were between 4 and 7 months postpartum reported having a panic attack in the previous month, although only $1.5 \%(n=12)$ were diagnosed with PD by using a standard clinical interview for $D S M-I V$. All participants had at least moderate symptoms of depression. ${ }^{32}$ The most commonly reported panic symptoms did not appear to be different from PD in the general population and included palpitations, sweating, trembling, feeling as they were going to die, and choking. ${ }^{32}$ Although this study had a prospective design and was generalizable to postpartum women in the community, the panic symptoms were assessed cross-sectionally; thus, the presence of symptoms prior to 4 months and after 7 months postpartum, as well as the longitudinal course of these symptoms, is unclear.

In a descriptive phenomenological study of six women, who experienced their initial onset of PD during the postpartum period, symptoms of panic were interpreted in the context of their postpartum state..$^{33}$ Participants reported feeling unable to leave their homes to take their children to groups and activities and being worried about the long-term impact of their PD and the resulting isolation of their children. ${ }^{33}$ The women endured distressing symptoms, such as chest pain, palpitations, shortness of breath, dizziness, tightening of throat, blurry vision, amplified sounds, and tingling in extremities: "like somebody injected Coca-Cola into my veins", ${ }^{33}$ in addition to heart-wrenching guilt and disappointment with themselves. Four out of six women were diagnosed with postpartum depression, and all women were diagnosed with PD; further, five out of six mothers were taking prescribed medication for their conditions. Mothers may be misdiagnosed with postpartum depression, when in fact they are suffering from the postpartum onset of PD. ${ }^{33}$ Women who met diagnostic criteria for postpartum depression indicated that the panic attacks they experienced were harder to bear than depressed mood. ${ }^{34}$ More research is needed to gain and place, within the postpartum context, descriptions of 
women's experiences with new onset of PD and to understand what impact this disorder may have on the quality of life of the new mothers and their infants.

\section{Characteristics of OCD}

This disorder is characterized by intrusive images or thoughts (obsessions) as well as repetitive behaviors or thought patterns (compulsions). Usually, obsessions are anxiety provoking, and compulsions are aimed at temporarily reducing anxiety. ${ }^{24}$ The perinatal period is a time of high risk for the onset of OCD..$^{35}$ It has been reported that obsessions in perinatal women often include intrusive thoughts of intentionally or accidentally harming the baby ${ }^{36}$ Mothers suffering from OCD may feel embarrassed about these thoughts and disinclined to discuss their symptoms with care providers, thus making misdiagnosis common. ${ }^{37}$ Yet, it is important to note that thoughts about harming the baby, at a subclinical level, may also be a normal feature of new parenthood and may cause the parent to be vigilant in protecting the baby from potential harm. ${ }^{38}$ Thus, the boundaries between adaptive, subclinical symptoms, and a functionally impairing disorder are often difficult to define. ${ }^{39}$

\section{Women's experiences with postpartum OCD}

Arnold $^{36}$ described new onset of OCD in seven postpartum women with a previous history of other psychiatric disorders. All of the participants reported aggressive obsessions that involved their babies. While none of the women acted on their obsessions to harm the infants, five out of seven women reported to modify their behavior around their babies, resulting in an inability or refusal to care for them. ${ }^{36}$ Some women showed avoidance, others exhibited excessive involvement: one woman took her baby for frequent health checkups, and another did not allow anyone to hold her infant because of fear of something bad happening to the baby: "I wish he [baby] was back in my belly". ${ }^{36}$

However, in a sample of 47 postpartum women with symptoms of both OCD and depression, the thought content excluded infant harm. ${ }^{32}$ In contrast, participants often endorsed compulsive cleaning and checking behaviors, without aggressive urges to harm the infant. The researchers found that compulsive hand washing or cleaning behavior was attributed to concern that the infant would be exposed to germs. The study did not include a structured tool to probe thoughts about infant harm. Furthermore, data collection was conducted over the phone, and as a result, participants may not have felt comfortable reporting these thoughts, especially if they were not directly asked about them.
In another prospective cohort study from the USA, researchers also suggested that comorbid depression is common among postpartum women with syndromal and subsyndromal OCD. ${ }^{39}$ Out of 461 new mothers who were self-screened for OCD, anxiety, and depression, 52 (11\%) screened positive for OCD at 2 weeks postpartum, and an additional 22 (5.4\%) developed new OCD at 6 months postpartum. ${ }^{39}$ Furthermore, depression and anxiety scores were higher in women who screened negative for OCD with subclinical symptoms compared to women without OCD symptoms ( $p<0.001$ for both), and higher in OCDpositive women compared to women with subclinical OCD symptoms ( $p<0.001$ for both) ${ }^{39}$ Furthermore, 173 women, who screened negative for OCD, also experienced some obsessions and compulsions. In this OCD-negative group, the prevalence of specific obsessions and compulsions was similar between 2 weeks and 6 months postpartum, with concerns about dirt and germs being the most common obsession, and checking about not making a mistake being the most common compulsion. The study findings may be limited by the use of self-reported screens for OCD, anxiety, and depression that were not confirmed with clinical diagnostic interview. Abramowitz et al ${ }^{38}$ used selfreported instruments to delineate the relationship among depression, anxiety, and OCD in 60 postpartum women seeking treatment in an obstetrical mood disorder clinic. The participants were referred to the clinic at various points during the first 12 months postpartum. The researchers concluded that severity of OCD symptoms was moderately related to both depressive and anxious symptoms, with 23 women exhibiting clinically significant levels of OCD. ${ }^{38}$ While the researchers reported that the mean score for all participants who completed the screen for depression was 14.6 (cutoff score of $\geq 11$ being a positive screen), it was unclear how many participants had a clinically significant level of depression. In women with OCD, the most prevalent obsessive thoughts included fears of sudden infant death syndrome (SIDS) (57\%), infant being harmed by germs or poison (32\%), and slapping or shaking the infant (15\%).

The participants reported the following neutralizing strategies in response to their obsessions: frequent checking on the infant, trying to rationalize thought, and obtaining social support and prayer, with avoidance of the infant being fairly rare $(10 \%)$. While the findings indicate the need to assess for both depressive and anxiety symptoms in the postpartum period, the researchers acknowledged several limitations in this study: the participants were patients at an obstetrical 
psychiatric clinic and may have been at higher-than-average risk for psychiatric disorders; anxiety was not measured by a structured diagnostic tool; and participants were recruited at various points during their first-year postpartum. ${ }^{38}$

\section{Characteristics of PTSD}

This anxiety disorder was initially described in American soldiers who served in the Vietnam War. ${ }^{40}$ It is characterized by exposure to a traumatic event that a person deems could result in serious injury or death, and it is accompanied by intense fear or helplessness. ${ }^{24}$ The two most common features of childbirth that can make it potentially traumatizing for some women are extreme pain and a sense of loss of control. ${ }^{41}$ The $D S M-5^{24}$ does not identify childbirth as an example of a traumatic event that could result in PTSD, and many health care professionals may not recognize the signs of psychological and emotional trauma during childbirth due to their perception that birth trauma is a physical injury. ${ }^{42}$ Yet, as Beck ${ }^{43}$ eloquently argued, "the birth trauma lies in the eye of the beholder", implying that birth trauma is what women themselves perceive to be traumatic during their childbirth experience.

\section{Women's experiences with PTSD}

Two qualitative reports suggest that childbirth can qualify as a traumatic event that results in PTSD in some women. ${ }^{43,44}$ Ayers ${ }^{44}$ used thematic analysis to explore how thoughts and emotions about childbirth differed between women with PTSD $(n=25)$ and women without PTSD symptoms $(n=25)$ at 3 months postpartum. Study participants were selected from a sample recruited for the purposes of a larger longitudinal quantitative study and were matched for obstetric events, age, and parity. Compared to women without PTSD symptoms, women who screened positive for PTSD on a self-report scale reported more panic, anger, thoughts of death, mental defeat, and dissociation during birth, as well as painful and intrusive memories during the postpartum stage. ${ }^{44}$ Participants in the PTSD group actively avoided situations that would remind them of birth, for example, watching a woman giving birth on television, entering a hospital, or breastfeeding. While it is difficult to be certain about causality in this study due to its qualitative design, the researcher concluded that women may be more likely to develop PTSD if their childbirth experience included panic, thoughts of death, and dissociation. ${ }^{44}$

Furthermore, in a phenomenological study of 38 women, whose time since childbirth ranged from 6 weeks to 14 years, childbirth experience was also perceived as traumatic. ${ }^{43}$ All of the women had complicated childbirth experiences, and the diagnosis of PTSD was made by mothers' self-report that the disorder was identified by a health care professional. Perceived lack of communication and support by labor and delivery staff also contributed to participants' appraisal of a traumatic childbirth. ${ }^{43}$ Specifically, one woman recounted as follows: "the hospital staff discussed my baby's possible death in front of me just as if I weren't there". ${ }^{43}$ Participants felt trapped in their vivid memories of traumatic birth and described their symptoms as terrifyingly realistic nightmares, anger, anxiety, depression, dissociation, numbness, and suicidal thoughts. Traumatic childbirth experiences prompted four women to avoid future childbearing; several women abstained from sexual activities with their partners because intercourse resulted in flashbacks of pain and distress during labor. Several participants avoided their infants, sometimes for several years, as the baby was a stimulus for reexperiencing the traumatic delivery; some women avoided other mothers and babies, which resulted in increased maternal isolation. ${ }^{43}$ While women's accounts in both studies are compelling, the results are limited by reliance on self-report to measure PTSD, as well as by the cross-sectional description of symptoms.

\section{Discussion}

The aim of this article is to review the literature on women's experiences with postpartum anxiety. The review is limited by the quality of the available research evidence. First, few studies have examined women's experiences with postpartum anxiety disorders as defined by established diagnostic criteria, and the measures used to assess anxiety varied from study to study. For example, in the case of PTSD, no distinction was made between appraising a birth as being traumatic and clinically meeting the DSM-5 criteria for diagnosis for PTSD. Second, there was a lack of prospective longitudinal studies that determined precise times within the postpartum period when the risk of onset of anxiety is highest. No clear pattern emerged regarding the trajectory of symptoms of anxiety disorders during the postpartum period. Third, several studies were conducted in psychiatric clinic settings with participants receiving interventions for their anxiety disorder. ${ }^{2,36,38}$ Thus, the studies were not conducted specifically to assess postpartum anxiety in a community sample representative of all childbearing women. Last, most of the studies were conducted with married, white, middle-income, well-educated participants, therefore, the findings of this review may not reflect the experiences of postpartum anxiety disorders in 
other groups of women who differ in socioeconomic/ethnic status and raise their children without a partner. In spite of these limitations, the research indicates that anxiety disorders are common during the postpartum period. However, universal assessment for anxiety disorders has not been implemented as a routine part of postpartum care. ${ }^{11}$ It may be important to include effective assessment instruments for anxiety disorders in postpartum care, as well as to educate health care providers to address these psychological issues either at a primary care level or through timely referral to obstetrical mental health professionals. Raising public awareness about postpartum anxiety disorders is also beneficial, so that new mothers can seek appropriate help should they develop symptoms of anxiety during postpartum period.

Furthermore, while the available evidence suggests that clinical symptoms of postpartum anxiety disorder may have important implications for the mother-infant relationship, ${ }^{2,33,36,43}$ the nature of these disruptions (ie, the relationship between severity of maternal distress and infant development) remains underinvestigated. Future longitudinal studies with rigorous screening and diagnostic methods are needed to examine the symptoms of GAD, PD, OCD, and PTSD throughout the postpartum period, as well as their effect on social functioning of the new mother and the relationship between mother and her baby.

\section{Conclusion}

In this paper, I conducted a narrative review of the available literature on women's experiences with postpartum GAD, PD, OCD, and PTSD. The findings suggest that all postpartum anxiety disorders may have a detrimental effect on the mother and her family. Many mothers had more than one anxiety disorder, which were often also accompanied by postpartum depression. Most research so far focused on the prevalence rates of postpartum anxiety disorders, and evidence about clinical and subclinical symptomatology of postpartum anxiety disorders and their impact on motherbaby relationship is limited.

Large, prospective, longitudinal studies of women from various socioeconomic and ethnic backgrounds, which examine the nature, risk factors, trajectory, and consequences of clinically diagnosed anxiety disorders, are essential for the effective recognition and treatment of postpartum anxiety.

\section{Disclosure}

The author reports no conflicts of interest in this work.

\section{References}

1. Holmstrom R. Professionals must recognize the needs of anxious mothers. Pr Health Care. 2010;20:6-7.

2. Brockington I, Macdonald E, Wainscott G. Anxiety, obsessions and morbid preoccupations in pregnancy and puerperium. Arch Womens Ment Health. 2006;9(5):253-263.

3. Anniverno R, Bramante A, Mencacci C, Durbano F. New Insights into anxiety disorders. In: Durbano F, editor. Anxiety Disorders in Pregnancy and the Postpartum Period. London, UK: INTECH Open Access Publisher; 2013:260-285.

4. Heron J, O'Connor T, Evans J, Golding J, Glover V; The ALSPAC Study Team. The course of anxiety and depression through pregnancy and the postpartum in a community sample. J Affect Disord. 2004;80(1): 65-73.

5. Agrati D, Browne D, Jonas W, et al; MAVAN Research Team. Maternal anxiety from pregnancy to 2 years postpartum: transactional patterns of maternal early adversity and child temperament. Arch Womens Ment Health. 2015;18(5):693-705.

6. Lonstein J. Regulation of anxiety during the postpartum period. Front Neuroendocrinol. 2007;28(2-3):115-141.

7. Fairbrother N, Young A, Janssen P, Antony M, Tucker E. Depression and anxiety during the perinatal period. BMC Psychiatry. 2015;15: 206-213.

8. Teissedre F, Chabol D. Postnatal depression: a study of the predictive effects of postnatal anxiety. Irish J Psychol Med. 1991;20:111-114.

9. Dennis C. Identifying predictors of breastfeeding self-efficacy in the immediate postpartum period. Res Nurs Health. 2006;29(4):256-268.

10. Nayak M, Milner J. Neuropsychological functioning: comparison of mothers at high-and low-risk for child physical abuse. Child Abuse Negl. 1998;22(7):687-703.

11. Kingston D, Tough S, Whitfield H. Prenatal and postpartum psychological distress and infant development: a systematic review. Child Psychiatry Hum Dev. 2012;43(5):683-714.

12. Barnett B, Schaafsma M, Gusman A, Parker G. Maternal anxiety: a 5-year intervention study. J Child Psychol. 1991;32(3):423-438.

13. Wenzel A, Haigen E, Jackson L, Brendle J. Anxiety symptoms and disorders at eight weeks postpartum. J Anxiety Disord. 2005;19(3):295-311.

14. Britton J. Maternal anxiety: course and antecedents during the early postpartum period. Depress Anxiety. 2008;25(9):793-800.

15. Wenzel A, Haugen E, Jackson L, Robinson K. Prevalence of generalized anxiety at eight weeks postpartum. Arch Womens Ment Health. 2003; 6(1):43-49.

16. Dennis C, Coughlan M, Vigod S. Can we identify mothers at-risk for postpartum anxiety in the immediate postpartum period using the StateTrait Anxiety Inventory? J Affect Disord. 2013;150(3):1217-1220.

17. Wardrop A, Popadiuk N. Women's experiences with postpartum anxiety: expectations, relationships, and sociocultural influences. Qual Rep. 2013;18(6):1-24.

18. Rowe H, Fisher J, Loh W. The Edinburg Postnatal Depression Scale detects but does not distinguish anxiety disorders from depression in mothers of infants. Arch Womens Ment Health. 2008;11:103-108.

19. Cronin P, Ryan F, Coughlan M. Undertaking a literature review: a stepby-step approach. Br J Nurs. 2008;17(1):38-43.

20. Coughlan M, Cronin P, Ryan F. Step-by-step guide to critiquing research: part 1: quantitative research. Br J Nurs. 2007;16(11):658-663.

21. Davies P, Boruch R. Does for public policy what Cochrane does for health. BMJ. 2001;323:294.

22. Yuan Y, Hunt H. Systematic reviews: the good, the bad, and the ugly. Am J Gastroenterol. 2009;104(5):1086-1092.

23. Critical Evaluation Tools Programme (CASP) [webpage on the Internet]. Oxford, UK; 2018. Available from: http://www.casp-uk.net/ casp-tools-checklists. Accessed February 1, 2018.

24. American Psychiatric Association. Diagnostic and Statistical Manual of Mental Disorders. 5th ed. Washington, DC: American Psychiatric Association; 2013. 
25. Glasheen C, Richardson G, Fabio A. A systematic review of the effects of postnatal maternal anxiety on children. Arch Womens Ment Health. 2010;13(1):61-74

26. Clark K, Saville N, Bhandari B, et al. Understanding psychological distress among mothers in rural Nepal: a qualitative grounded theory exploration. BMC Psychiatry. 2014;14:60.

27. Coates R, Ayers S, de Visser R. Women's experiences of postnatal stress: a qualitative study. BMC Pregnancy Childbirth. 2014;14:359.

28. Hignet N, Stevenson A, Purtell C, Coo S. Qualitative insights into women's personal experiences of perinatal depression and anxiety. Women Birth. 2014;27(3):179-184.

29. Affonso D, Mayberry L, Sheptak S. Multiparity and stressful events. J Perinatol. 1988;8(4):312-317.

30. Martini J, Petzoldt J, Einsle F, Beesdo-Baum K, Hofler M, Wittchen H. Risk factors and course patterns of anxiety and depressive disorders during pregnancy and after delivery: a prospective-longitudinal study. J Affect Disord. 2015;175:385-395.

31. Affonso D, Liu-Chiang C, Mayberry J. Worry: conceptual dimensions and relevance to childbearing women. Health Care Women Int. 1998;20(3):227-236.

32. Wenzel A, Gorman L, O'Hara M, Stuart S. The occurrence of panic and obsessive compulsive symptoms in women with postpartum dysphoria: a prospective study. Arch Womens Ment Health. 2001;4(1):5-12.

33. Beck C. Postpartum onset of panic disorder. J Nurs Scholarsh. 1998; 30(2):131-135.

34. Matthey S, Barnett B, Howie P, Kavanagh D. Diagnosing postpartum depression in mothers and fathers: whatever happened to anxiety? J Affect Disord. 2003;74(2):139-147.
35. Vythilingum B. Anxiety disorders in pregnancy and the postnatal period. Contin Med Educ. 2009;27(10):450-452.

36. Arnold L. A case series of women with postpartum-onset obsessivecompulsive disorder. J Clin Psychiatry. 1999;1(4):103-108.

37. Johnson K. Obsessive-compulsive disorder in the perinatal period. Int J Childbirth Educ. 2013;28(1):26-31.

38. Abramowitz J, Meltzer-Brody S, Leserman J, et al. Obsessional thoughts and compulsive behaviours in a sample of women with postpartum mood symptoms. Arch Womens Ment Health. 2010;13:523-530.

39. Miller E, Hoxha D, Wisner K, Gossett D. Obsessions and compulsions in postpartum women without obsessive compulsive disorders. $J$ Womens Health. 2015;24(10):825-830.

40. Pitman R, Altman B, Macklin M. Prevalence of posttraumatic disorder in wounded Vietnam veterans. Am J Psychiatry. 1989;146(5):667-669.

41. Reynolds J. Post-traumatic stress disorder after childbirth: the phenomenon of traumatic birth. CMAJ. 1997;156(6):831-835.

42. Elmir R, Schmied V, Wilkes L, Jackson D. Women's perceptions and experiences of a traumatic birth: a meta-ethnography. J Adv Nurs. 2010; 66(10):2142-2153.

43. Beck C. Post-traumatic stress disorder due to childbirth: the aftermath Nurs Res. 2004;53(4):216-224.

44. Ayers S. Thoughts and emotions during traumatic birth: a qualitative study. Birth. 2007;34(3):253-263.
International Journal of Women's Health

\section{Publish your work in this journal}

The International Journal of Women's Health is an international, peerreviewed open-access journal publishing original research, reports, editorials, reviews and commentaries on all aspects of women's healthcare including gynecology, obstetrics, and breast cancer. The manuscript management system is completely online and includes

\section{Dovepress}

a very quick and fair peer-review system, which is all easy to use. Visit http://www.dovepress.com/testimonials.php to read real quotes from published authors.

\footnotetext{
Submit your manuscript here: http://www.dovepress.com/international-journal-of-womens-health-journal
} 